\author{
Igor Mikecin \\ Sveučilište u Zagrebu, Filozofski fakultet, Ivana Lučića 3, HR-10000 Zagreb \\ imikecin@ffzg.hr
}

\title{
Suprotnost rata i mira u Heraklita
}

\begin{abstract}
Sažetak
Polazeći od gnome B 53 DK, koja u hrvatskom prijevodu glasi: "Rat svih otac je i svih kralj, i jedne kao bogove iskaza, a druge kao ljude, jedne sužnjevima učini, a druge slobod-

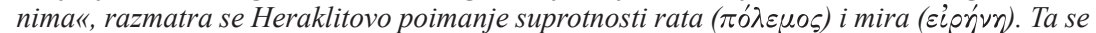
suprotnost javlja u gnomi B 67 kao jedna od temeljnih suprotnosti, u kojoj se obrće bivanje

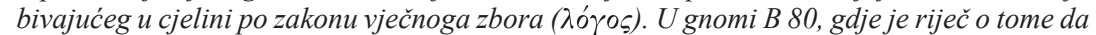

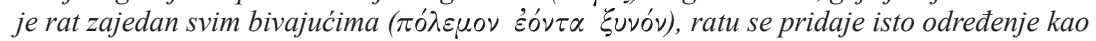
i samomu zboru. Rat nije samo u suprotnosti prema miru nego i prema skladu (ápuovín), pri čemu su to dva temeljna, međusobno suprotna i supripadna određenja zbora kao onoga istoga u odnosu suprotnosti uopće. Rat se, dakle, promatra u cijelom rasponu njegova očitovanja od rata među ljudima i bogovima preko sukoba unutar svakog pojedinog bivajućeg i među bivajućima u cjelini, sve do vrhovnoga zakona prema kojem sva bivajuća bivaju. U svezi s pojmom rata razmatra se također i s njime neposredno povezan pojam spora ili

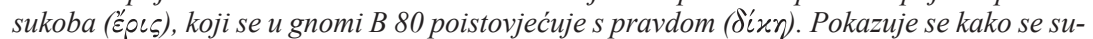

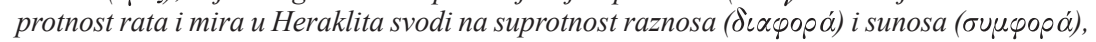
odnosno razdvajanja i sjedinjavanja, koja je u osnovi bivanja bivajućeg u cjelini.
\end{abstract}

\section{Ključne riječi}

Heraklit, rat, mir, zbor, sklad, sukob, pravda, raznos, sunos

Što se u Heraklita ima misliti pod ratom, otkriva nam ponajprije gnoma koju je prenio Hippolyt Rimski (Ref. omn. haer. IX, 9, 4):

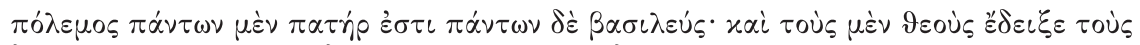

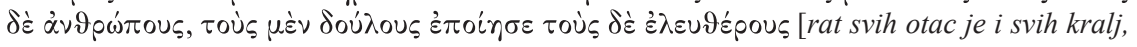
i jedne kao bogove iskaza, a druge kao ljude, jedne sužnjevima učini, a druge slobodnima (B 53) $]^{1}$

Odmah valja uočiti: riječ $\pi \dot{\alpha} \nu \tau \omega \nu$ ne odnosi se samo na ljude i bogove - rat nije samo, kao Zeus u Homera, otac i kralj svih ljudi i bogova (Hom. Il. II,

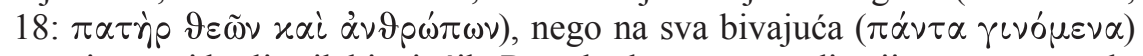
- rat je otac i kralj svih bivajućih. Rat, shodno tomu, ovdje nije samo rat među ljudima, među bogovima, te između ljudi i bogova, nego i mnogo više od toga: rat unutar svakog pojedinog bivajućeg, rat među bivajućima, rat cjeline bivajućih ili svijeta, i napokon vrhovni zakon svega bivanja, po kojem sva bivajuća bivaju, a to je zakon istosti i ujednosti protivnoga. Taj nepojavni i skriveni smisao rata je u Heraklita prvotan, a onaj njegov pojavni i bjelodani

Heraklitove se gnome označavaju prema rasporedu u Dielsovom izdanju. Hermann Diels,
Walther Kranz, Die Fragmente der Vorsokratiker I, Weidmann, Berlin ${ }^{6} 1951$. 
smisao, na koji se isprva i najčešće pomišlja, istom proizlazi iz toga prvotnoga, na njemu počiva i njega u sebi skriva.

Pri tome pojavni rat, u kojem se ljudi oružjem sukobljavaju i usmrćuju, nije puka metafora onoga nepojavnog rata. U metafori naime ono osjetilno služi tek kao slika čiji se smisao prenosi na ono nadosjetilno, i to tako da ta slika kao nešto sporedno uzmiče pred uzorom koji odslikava. Ovdje je naprotiv pojavni rat znamen $(\sigma \tilde{\eta} \mu \alpha)$ nepojavnoga rata, stojeći u potpunome srazmjerju s njime. Kao pojava on je upravo pojava onog nepojavnog samog, ono u kojem i kroz koje se samozatajno bivstvo rata pojavljuje i ujedno sebe taji.

Ratu Heraklit pridijeva dva pridjevka koji u grčkome bogoslovlju pripadaju

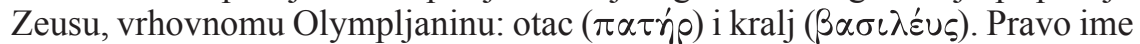
za ono koje mnogoznalci u svojem neznanju imenuju Zeusom jest Polemos. Rat naime nije nijedno od bivajućih, pa tako ni sam vrhovni bog, nego ono jesuće, kojemu sva bivajuća duguju svoje rođenje i način svoga bivanja.

Spomen munje u Heraklita, u kojoj se krije oružje Zeusovo, nužno kazuje i o ratu kao kralju svih bivajućih:

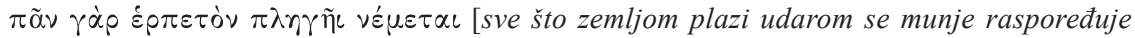
(B 11)];

i:

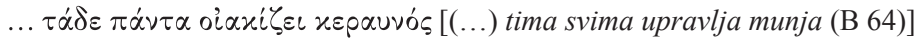

Ono pak koje upravlja svima isto je što i ono mudro i njegova božanska znatba:

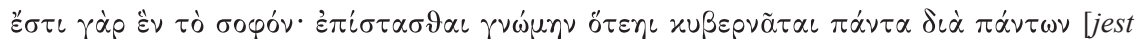
naime jedno ono mudro: umjeti znatbu kojom se krmane sva kroza sva (B 41)]

Ukoliko je očinstvo i kraljevstvo rata istina očinstva i kraljevstva Zeusova, koja se prikriva onima koji nisu prisni onomu mudrom, utoliko gnoma koja kazuje

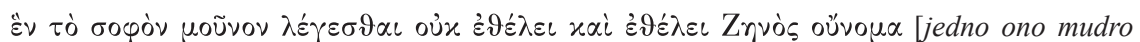
jedino zboriti se ne će $i$ hoće Zeusa imenom (B 32)]

otkriva da je rat ustvari pobliže određenje onog jednog jedinog mudrog. Uzme

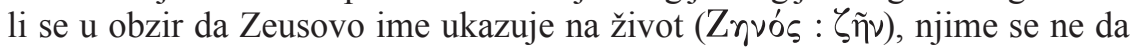
zboriti rat kao ono smrtonosno, ali je ono ujedno i djelu rata primjereno ime utoliko što rat ne donosi samo smrt nego i čuva život.

Ima li se na umu da ono mudro nije drugo nego ono prvotno ( $\tau \grave{o} \pi \rho \tilde{\omega} \tau o v)$ ili istina zbora ( $\lambda$ ó$\circ \varsigma$ ), nimalo ne iznenađuje da se u drugoj od triju gnoma $u$ kojima se izričito spominje $\pi$ ó $\varepsilon \varepsilon \mu \circ \varsigma$ ratu pridijeva pridjev $\zeta u v o ́ \varsigma$ 'zajedan':

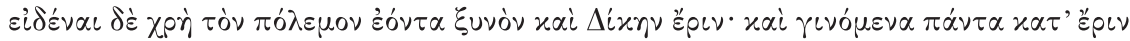

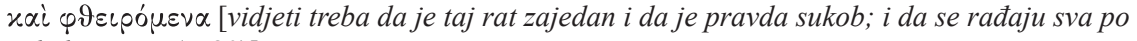
sukobu i ginu (B 80)]

Ono zajedno je naime jedno od glavnih određenja samoga zbora:

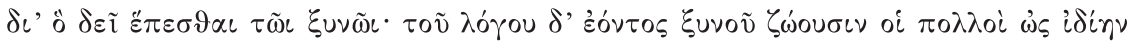

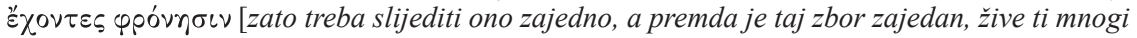
kao da vlastiti imaju razbor (B 2)]

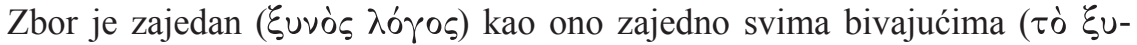

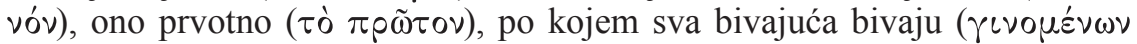

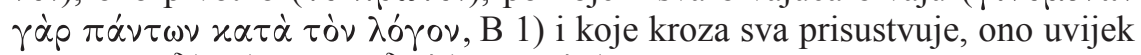

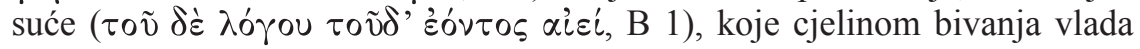




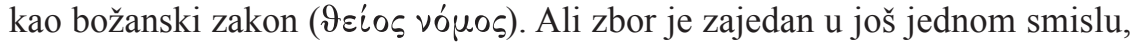
u kojem se on i može poistovjetiti s ratom. Sva bivajuća naime bivaju kao suprotna i u suprotnosti ( $\gamma^{\prime} \nu \varepsilon \sigma \vartheta \alpha \iota \tau \varepsilon \pi \alpha^{\prime} \nu \tau \alpha \varkappa \alpha \tau^{\prime} \varepsilon^{\prime} \nu \alpha \nu \tau \iota \iota^{\prime} \tau \eta \tau \alpha$, Diog. Laert. IX, 8). Bivanje u cjelini zbiva se kao suproćenje. Suprotnost ono jednog kao onog jesućeg i onih svih kao onih bivajućih u osnovi je svih mogućih suprotnosti među bivajućima. A zbor je ono sjedinjujuće svih bivajućih, a time i svih mogućih suprotnosti. Ona suprotna uvijek su ujedno i zajedno zato što se bivanje neprestano obrće kroz mnoštvo suprotnosti, shodno zboru kao onomu jednom sva objedinjujućem. Rat stoga nije drugo nego pobliže određenje zbora kao onog zajednog. On je svima zajedan utoliko što je ono zajedno u svim suprotnostima bivanja, ono što ona suprotna bivajuća drži zajedno i ujedno.

Među svim suprotnostima koje se u ratu pokazuju ističe se suprotnost božanskog i ljudskog, slobodnog i ropskog. Čovjek kao ono bivajuće koji zborom svoje duše može suzboriti sa zborom samim jest u sebi samome iznimno poprište rata i mira. Ukoliko mu je biti tako da ljubi ono mudro (àvìp

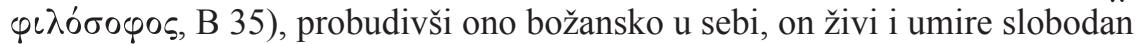
ratujući za istinu zbora, jer zakonitost zbora iziskuje borbu u kojoj se spašava od utaje:

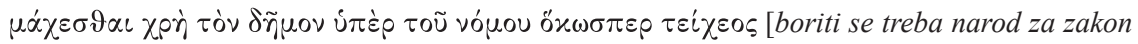
kano za zidine (B 44)]

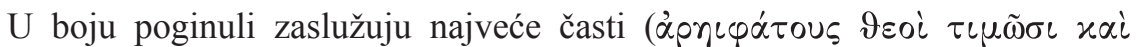

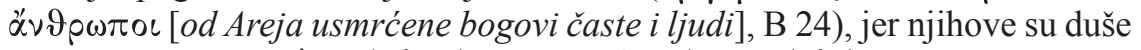

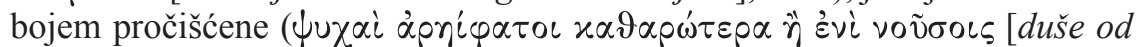
Areja usmrćene čistije (su) nego u bolestima (B 136)].

Blizina i daljina Heraklitove mudrosti i homerskoga bogoslovlja izlazi na vidjelo upravo u poimanju rata. U 18. pjevanju Iliade (XVIII, 284-309) Hektor, suprotstavljajući se Polydamantovom savjetu da se Trojanci imaju povući u grad i ne čekati Achajce izvan zidina jer se Achillej, rasrđen Patrokolovom smrću, vratio u boj na strani Achajaca, zahtijeva da Trojanci zadrže položaj i započnu bitku kod achajskih lađa, te kaže kako neće bježati od ratne vreve, nego će stati nasuprot Achilleju, u borbi u kojoj svatko može odnijeti pobjedu jer Enyalij je onim međusobno zaraćenima zajedan, donoseći smrt i onima

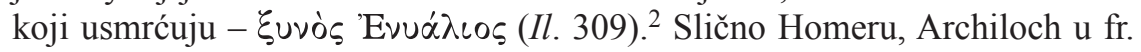
38 D, što ga je prenio Klement Alexandrijski u Prostirkama (Strom. VI. 6, 1), kaže:

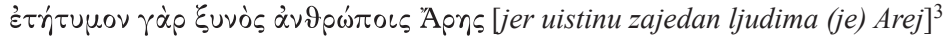

Iskazujući da je rat zajedan ('̌uvós), Homer i Archiloch doduše slute ono istinito, ali im je skriveno da je rat svemu zajedan zbor, kao što im je skriveno i to da ono čemu je rat zajedan nisu tek ljudi, nego sva bivajuća.

Premda Archiloch Enyalija štuje ne manje nego Mouse pjevajući:

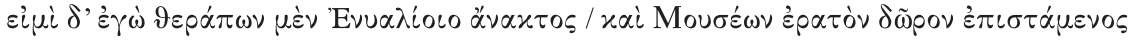
[ja sam službenik Enyalija gospodara / i ljupkoga dara Mousa znalac (fr. 1 D)];

Enyalij je u Homera pridjevak Arejev (Il. XVII, 211), a ponekad stoji i umjesto toga imena (Il. XIII, 519; XX, 69). Kasnije se javlja i kao zaseban bog rata, sin Areja i njegove pratilje Enyo - od koje mu potječe i ime.
3

Archilochovi se fragmenti navode prema izdanju: Ernestus Diehl (ur.), Anthologia Lyrica Graeca I.3, Teubner, Leipzig 1952. 
ili:

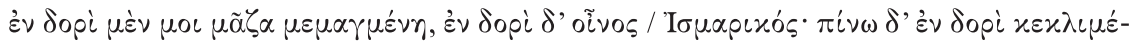
vos [u koplju je meni ječmenica zamiješana, u koplju vino / ismarsko, pijem o koplje oslonjen (fr. 2 D)];

ipak je spreman učiniti nešto nečuveno za drveni ep - odbaciti svoj štit pobjegavši iz bitke, kako bi spasio život:

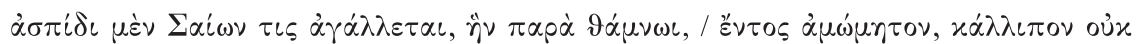

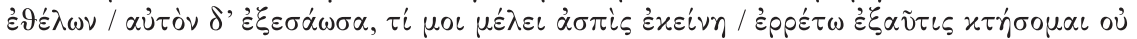

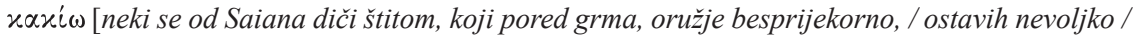
a sebe spasih, što me briga za taj štit? / neka ode; opet ću steći ne lošiji (fr. 6 D) $]^{4}$

Menelaj se u 13. pjevanju Iliade zgraža nad trojanskom žudnjom za ratom:

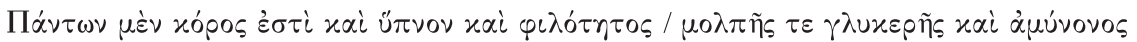

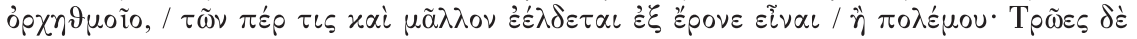

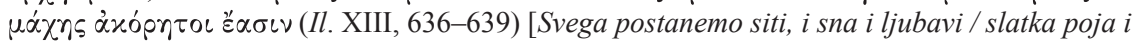
dražesna plesa / koji još $i$ više pobuđuju žudnju nego rat; a Trojanci su nezasitni borbe] ${ }^{5}$

A Agamemnon kori Achilleja što ljubi samo rat i ratovanje:

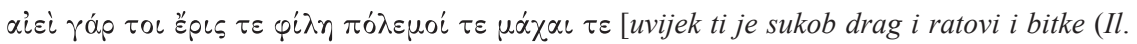
I, 177)]

U Homera je rat loš (xaxós, Il. I, 284; IV, 15, 82; XIII, 225; XVI, 494; XX,

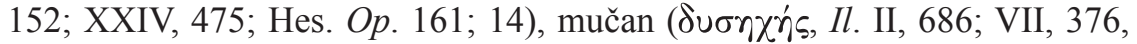

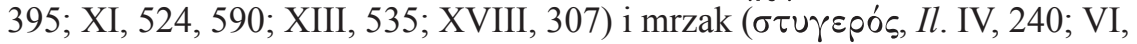
330; XVI, 723). Osim toga, Homer uz rat vezuje samo uništavanje, razaranje i smrt, a uz mir plodnost, blagostanje i život. Premda rat donosi čast i slavu, jer vrlina izlazi na vidjelo upravo u ratu, on je ipak pogubna nužda, koja svoju svrhu ima u miru.

Heraklit navodi 107. stih 18. pjevanja Iliade da potkrijepi Homerovo neznanje bivstva rata. Na tom mjestu u Iliadi Achillej, nakon Patroklove pogibije, svojoj majci Thetidi najavljuje povratak u boj protiv Trojanaca i konačni obračun s Hektorom. Pritom iskazuje želju da jednom zauvijek nestane razdora i žuči, što razborita čovjeka uvodi u srdžbu, jer mu je mnogo slađa od meda, uzdižući se u njegovim grudima poput dima. Aristotel u Eudemovoj etici (EE 1235a25), Plutarch u O Isidi i Osiridu (De Isid. et Osir. 370d), te Simplikij u Komentaru Aristotelovih Kategorija (In Categ. p. 412, 22 Kalbfleisch) izvještavaju o Heraklitovom prijekoru Homera:

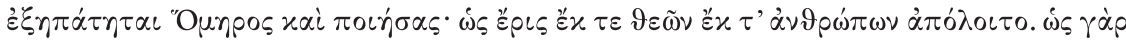

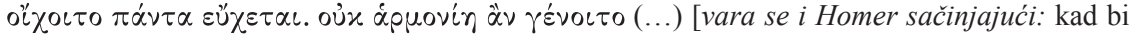
barem sukob iz bogova i iz ljudi nestao] (Il. XVIII, 107); [jer ište da sva iščeznu. Ne bi se naime (tada) rodio sklad (...) (A 22)] ${ }^{6}$

Homeru, koji ište da nestane sukob među bogovima i ljudima, skriva se to da time zaziva nestanak svih bivajućih jer se sva rađaju upravo iz sukoba onih suprotnih, a naposljetku iz suprotnosti rata i mira (vidi Plut. De Isid. et Osir. 370d). Homerova miroljubivost zaziva nestanak svega jer je rat otac svega $\mathrm{i}$ ničega ne bi uopće moglo biti bez rata, nije ni moguće da rata nema. Nijedno bivajuće nikako i nikada ne može umaknuti ratu. Stoga Heraklit kaže:

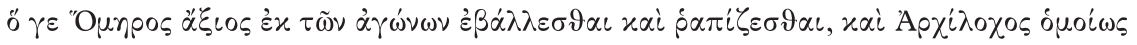
[taj Homer baš zaslužuje da bude iz borbe izbačen i išiban, i Archiloch isto (B 42)]

Oni naime ne razumiju da su rat $\mathrm{i}$ mir jedno $\mathrm{i}$ isto. A onima pak koji to ne razumiju nema mjesta u borbi $(\dot{\alpha} \gamma \dot{\omega} \nu)$. 
Rat je zakon bivanja, zajedan svemu bivajućem, njegova vladavina je sveopća. Po njemu sva bivajuća bivaju. Ukoliko sva bivaju u suprotnosti, utoliko ono zajedno svima dade se shvatiti kao ono zajedno suprotnima, odnosno ono zajedno svih kao ono zajedno suprotnih, kao njihovo jedinstvo i istost. Rat je zajedan time što razjedinjujući sjedinjuje ona suprotna.

Rat i mir suprotnih ne vladaju samo u nekom pojedinom bivajućem, ni među pojedinim bivajućima, nego tvore poredak cjeline bivajućeg. Dok rat iz jednoga izvodi sva, dotle ih mir svodi u jedno. Rat je razjedinjavanje onog jednog, a mir je sjedinjavanje svih. Suprotnost rata i mira u Heraklita svodi se tako na suprotnost seberazlučivanja ili seberaznošenja $(\delta \iota \alpha \varphi \varepsilon ́ p \varepsilon \sigma \vartheta \alpha \iota)$ i sebeslučiva-

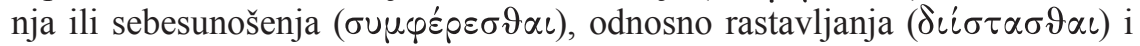
sastavljanja ( $\sigma u v i \sigma \tau \alpha \sigma \vartheta \alpha \iota)$, koja je u osnovi cjelokupnoga bivanja, a to znači nastanka i nestanka, preinake i prevrata, rasta i opstanka svega što biva. $\mathrm{O}$ svjetotvornom smislu rata i mira svjedoči Diogen Laertij:

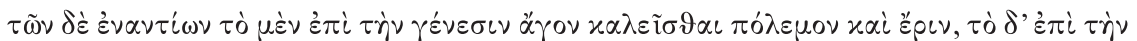

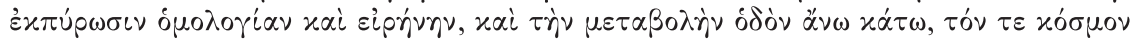

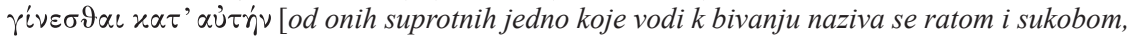
a drugo koje vodi $k$ izognjenju slogom i mirom. I premet je put gore dolje, a red biva po njemu (Diog. Laert. IX, 8)]

Ali i jedno i drugo, rat i mir, samo su nerazdvojni premeti istoga ognja:

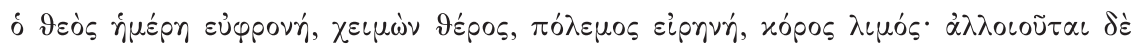

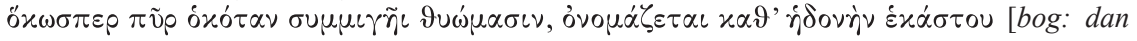
noć, zima ljeto, rat mir, sitost glad, a inači se kano oganj kada smiješa se s kadovima, imenuje se po slasti svakoga (B 67)]

Štoviše, oni sami su isto jer su jedinstvo razjedinjavanja i sjedinjavanja onoga svega i svih. Sva se ratom razjedinjuju i sjedinjuju pod vidom razjedinjavanja, a mirom pod vidom sjedinjavanja.

Shvati li se suprotnost razjedinjavanja i sjedinjavanja kao suprotnost razabiranja i sabiranja, može se reći da su rat i mir u Heraklita unutrašnje dvojstvo u zborenju samoga zbora. Rat i mir su tako dva temeljna, međusobno suprotna

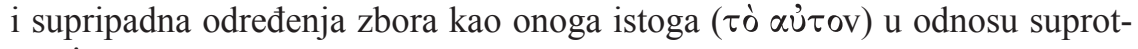
nosti.

Navodeći Heraklitov prijekor Homera Aristotel u Eudemovoj etici kaže kako su po Heraklitu ona suprotna prijateljska ( $\tau \dot{\alpha} \varepsilon \dot{\varepsilon} \nu \alpha \tau \tau^{\prime} \alpha \alpha \varphi^{\prime} \lambda \alpha$ ), a zatim dodaje:

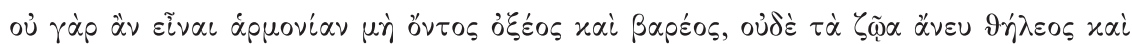

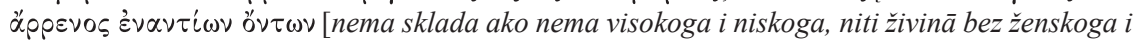
muškoga kao onih koji su suprotni (Arist. EE 1235a25-29)]

Tomu suprotno je mnijenje da su ona slična prijateljska, a ona suprotna nepri-

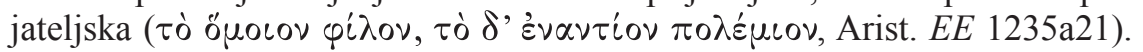
Dva primjera koja navodi Aristotel tiču se glazbenoga sklada glasova i poroda suprotnih spolova.

Plutarch izvještava da je Archiloch zbog tih stihova protjeran iz Sparte (vidi. Plut. Inst. Lac. 34, 239b).

5

Tekst Homerovih epova navodi se prema izdanjima: David Binning Monro, Thomas William Allen (ur.), Homeri Opera, I-II, Clarendon Press, Oxford 1963.; Thomas William
Allen (ur.), Homeri Opera, III-IV, Clarendon Press, Oxford 1963.

6

Iz navedenoga teksta fragment Heraklitove gnome vjerojatno čine samo riječi: (...) $\omega_{\varsigma}$

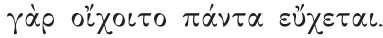


U Heraklita sklad (¿́puovín) međutim ima daleko širi smisao, koji se ne ograničava samo na glazbu. Sklad je naime svaki odmjereni odnos suprotnosti. Kada bi vladao samo mir bez rata, ne bi bilo sklada u bivanju. Sklad izrasta iz suprotnosti rata i mira kao što se iz suprotnosti visokih i dubokih glasova rađa skladna glazba. Prekomjerje mira i nedostatak rata vodi ne samo u nesklad bivanja, nego i u propast uslijed nerazlučenosti onih suprotnih. Ali obratno, prekomjerje rata vodi u krajnju razdvojenost i suprotstavljenost onih suprotnih.

O svezi sukoba i sklada riječ je u gnomi koju prenosi Aristotel u Nikomachovoj etici (1155b4):

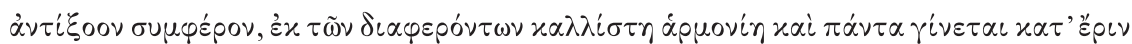
[ono protustremeće sunoseće, iz onih raznosećih najljepši sklad i sva bivaju po sukobu (B 8)]

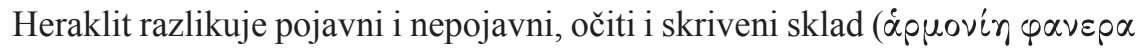

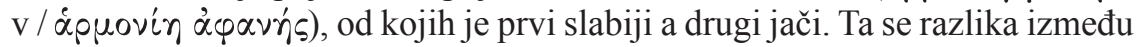
ostalog može shvatiti i kao razlika između manje lijepog i najljepšeg sklada

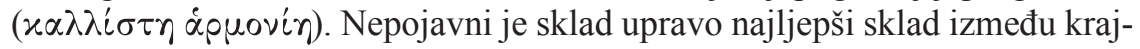
nje suprotnih koji se nalaze u razlučujućem slučivanju, razdvajajućem sjedinjenju, doslovno raznosećem snošaju. Za razliku od toga pojavnomu skladu nedostaje ljepote jer u njemu ne vlada krajnja napetost između sjedinjavanja i razjedinjavanja onih suprotnih. Pojavni je sklad između onoga sličnoga i istoga, a nepojavni između različitoga i suprotnoga. Samo se na prvi pogled čini da se sklad suprotnih može jednostrano izjednačiti s mirom među njima. Uistinu je on samo ondje gdje s mirom zajedno ima i rata.

Taj skriveni i najljepši sklad isti je onaj koji se naziva povratnim:

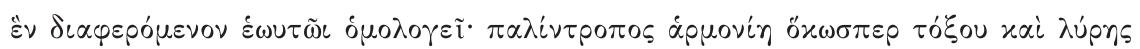
[jedno seberaznoseće sa samim sobom suzbori: povratni sklad kano u luka i lire (B 51)]

Luk i lira su uzoriti znameni sklada, koji ponajbolje znamenuju da je sklad u sebi samome dvojan: rat i mir. Luk je naime ratno oružje, ono bivajuće kojim se vodi rat, a lira je sredstvo mira, kojim se u miru glazbuje. Zajedno luk i lira znamenuju suprotnost rata i mira u samome skladu. No oni su već svaki u sebi samome suprotni, jer luk kroz ratovanje donosi i čuva mir, usmrćujući čuva

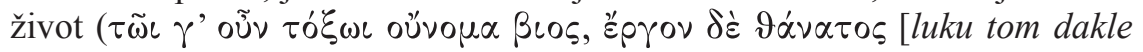
ime život, a djelo smrt, B 48], a lira ne umiruje samo nego ujedno i uznemiruje. No osim toga pojavnoga djelovanja oba ta bivajuća u sebi kriju sukob suprotnih težnji, koji ih uspostavlja i održava u njihovom opstanku. Kad krakovi luka i rogovi lire ne bi usuprot stremili, a to znači međusobno ratovali, ne bi strune koje ih sjedinjuju mogle biti toliko napete da svojom napetošću drže ona protivna zajedno i u miru, kako bi se iz luka mogla odapeti strijela, a iz lire odjeknuti glazba.

Kao što je pojavni rat zajedan stvarajući zajedništvo među onima koji ratuju i dovodeći one zaraćene do sraza, tako je i rat kao zakon svekolikog bivanja zajedan jer objedinjuje i spaja ona suprotna uopće. Rat nije samo razaranje i uništavanje nego je i stvaranje i očuvanje. Kao otac ( $\pi \alpha \tau \dot{\eta} \rho)$ rat je roditelj, vinovnik i začetnik svih bivajućih, onih koja se rađaju i umiru, nastaju i nestaju. To očinsko rađanje je neprestano tvorenje/proizvođenje ( $\pi$ oin $\sigma \iota \varsigma)$ koje iskazuje, pokazuje i iznosi na vidjelo, daje da se pojavi ono što proizvodi. Rat je vinovnik pojavljivanja bivajućeg kao bivajućeg, a potom i načina njegova pojavljivanja. Biti otac znači bivajuće iznositi na vidjelo u onome što i kako ono biva, razlučiti ga od drugoga bivajućeg, pokazati ga u njegovu bivstvu, 
učiniti onime kojim ono biva. Rat ne otkriva tek ono što već kao takvo opstoji i prije njega. Rat nije tek rat između nečega što već i neovisno o ratu opstoji, nego se kroz rat i u ratu tvore ona ratujuća, i to kao ona koja prije svega u sebi samima ratuju. No rat ne tvori samo ono bivajuće, nego ga i održava u njegovu bivanju. Biti kralj ( $\beta \alpha \sigma \iota \lambda \varepsilon u ́ \varsigma)$ je tako vladati onim stvorenim.

Uz suprotnost rata i mira tijesno je vezana suprotnost sukoba, spora ili razdora

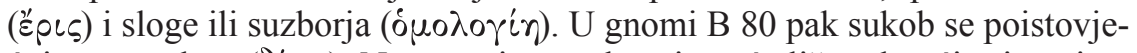
ćuje s pravdom $(\delta i x \eta)$. Na tu se istost ukazuje već sličnoglasećim imenima Ěpıs i 'Epıvús jer Erinyje su pomoćnice Pravde, koja čuva zakon suprotnosti kažnjavajući obijesni prijestup mjere, kada su suprotna međusobno neumjerena, bilo u pojedinom bivajućem ili među njima u cjelini uređenog bivanja (usp. B 94). Pri tome pravda ne nastupa nakon sukoba da bi kaznila prijestup, nego se ona zbiva upravo kao sukob.

Suproćenje nije samo razdor i sukob, u kojem jedno suprotno neprestano nadvladava drugo i opire mu se, nego je ujedno i sloga i suglasje, u kojem se jedno predaje drugomu, uzajamno se iziskujući. Prevratima sukobljenih suprotnih uvijek vlada određeni omjer koji je u neprestanoj mijeni. No kako god se taj omjer mijenjao, ona suprotna nužno ostaju uvijek srazmjerna. U tome je pravda njihova sukoba. Za neravnomjernom prevlašću jednoga slijedi njegov uzmak i prevlast drugoga prema zakonu odmazde ( $\dot{\alpha} \nu \tau \alpha \mu \circ \iota \beta \dot{\gamma})$. Ono koje biva suzbijeno i nadvladano uzmiče do određene mjere kada se suprotnost u sebi po pravdi obrće tako da ono prestaje uzmicati i ponovno provaljuje i nadire da bi istom mjerom uzvratilo drugomu suprotnom. Trenutak obrata vrhunac je prevlasti jednoga suprotnog nad drugim u njihovom sukobu.

Rat luči bogove i ljude. Za razliku od boga, kojemu su sva pravedna, ljudi luče ono pravedno od onoga nepravednog (B 102). Shodno tomu ljudima je u ratovanju i mirovanju moguća neumjerenost. Kada mir neumjereno prevlada nad ratom ili obratno rat nad mirom, to jest kada u samome ratu iščezava sloga, a u samome miru sukob, gubi se snaga sklada. Uzrok je tomu obijesno prekomjerje (üßpıs), koje valja gasiti prije negoli požar (B 43). Blagotvor-

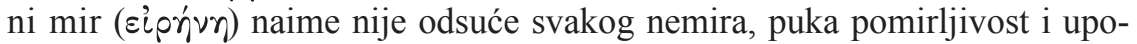
kojenost, u kojoj se neprimjetno krije razoran razdor, nego je krajnja napetost sabranosti, u kojoj se ona suprotna uzajamno drže u najljepšem skladu. U pravednome ratu pak, koji počiva na suglasju s ratovanjem svojstvenim samomu zboru (ó ò $_{0} \gamma_{i}(\eta)$, ne vlada bestidno razaranje i uništavanje onih sukobljenih, nego oni kroz sukob istom dospijevaju i borave u istini svoga bivstva.

\title{
Igor Mikecin
}

\section{Der Gegensatz von Krieg und Frieden bei Heraklit}

\begin{abstract}
Zusammenfassung
Ausgehend von der Gnome B 53 DK, die in der deutschen Übersetzung lautet: „Der Krieg ist von allem der Vater, von allem der König, und die einen erwies er als Götter, und die anderen als Menschen, die einen machte er zu Knechten und die anderen zu Freien", wird Heraklits

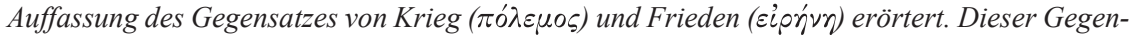
satz kommt in der Gnome B 67 zum Wort als einer der Grundgegensätze, in welchem sich das Werden des Werdenden im Ganzen gemäß dem Gesetz des ewigen Logos vollzieht. In der Gnome

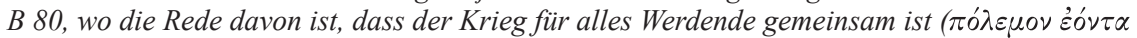
Guvóv), wird dem Krieg dieselbe Bestimmung zugesprochen, wie dem Logos selbst. Der Krieg steht nicht nur im Gegensatz zum Frieden, sondern auch zur Harmonie (̇́puovín), wobei diese zwei zueinander gegensätzlichen und zusammengehörenden Grundbestimmungen des Logos sind, der das Selbe im Gegensatzverhältnis überhaupt ist. Der Krieg wird also in seiner ganzen
\end{abstract}


Reichweite betrachtet, als Krieg zwischen Menschen und Göttern, als Streit innerhalb jedes einzelnen Werdenden und jedes einzelnen Werdenden und als das höchste Gesetz, als das höchste Gesetz des Werdens. Im Zusammenhang mit dem Begriff des Krieges wird auch der Begriff des

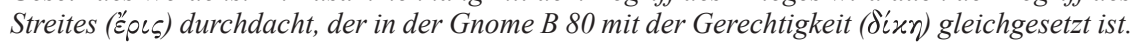
Es wird gezeigt, dass der Gegensatz von Krieg und Frieden bei Heraklit sich auf den Gegensatz

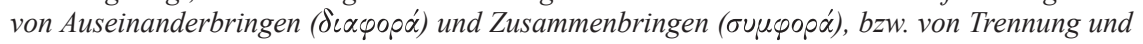
Vereinigung, zurückführen lässt, der dem Werden des Werdenden im Ganzen zugrunde liegt.

\section{Schlüsselwörter}

Heraklit, Krieg, Frieden, Logos, Harmonie, Streites, Gerechtigkeit, Auseinanderbringen, Zusammenbringen 